\title{
Combination of Sickle Cell and Alpha-Thalassemia Traits and In- cidence of Non-Atherosclerotic Myocardial Infarction in a Young Woman, Beyond Coincidence?
}

Lee S Nguyen ${ }^{1 *}$, Alban Redheuil' ${ }^{2}$, Olivier Mangin ${ }^{1}$ and Joe-Elie Salem ${ }^{1}$

${ }^{1}$ Department of Pharmacology and CIC-1421, Sorbonne Universités, Institute of Cardiometabolism and Nutrition (ICAN), France

${ }^{2}$ CardiovascularImaging and Interventional Radiology Department, Sorbonne Universités, Institute of Cardiometabolism and Nutrition (ICAN), France

"Corresponding author: Lee S Nguyen, Centre d'investigation Clinique, AP-HP, Pitié-Salpétrière, 52 Boulevard Vincent Auriol, 75013 Paris, France, Tel :+33 628214511 fax: +33 1 42178532, E-mail: lee.nguyen@aphp.fr

Citation: Nguyen LS, Redheuil A, Mangin O, Joe-Elie Salem (2016) Combination of Sickle Cell and Alpha-Thalassemia Traits and Incidence of Non-Atherosclerotic Myocardial Infarction in a Young Woman, Beyond Coincidence? Cardiolog Res Cardiovasc Med 1: 109. DOI: 10.29011/2575-7083.000009

Received Date: 29 November, 2016; Accepted Date: 15 December, 2016; Published Date: 20 December, 2016

\begin{abstract}
Alpha-Thalassemia trait and sickle trait are not commonly considered risk factors of ischemic heart disease. We report the case of a non-atherosclerotic silent myocardial infarction in a 46-year-old woman, carrier of the alpha-thalassemia trait (homozygous deletion of locus -3.7) combined with sickle cell trait. While the patient was included as healthy volunteer for a metabolic study, we performed cardiac magnetic resonance imagery showing a left ventricle apicolateral myocardial infarction. Coronary computed tomography angiography showed normal coronary arteries with a coronary calcium score of 0 . The patient was treated with low-dose aspirin in secondary prevention afterwards. This case allows us to discuss cardiovascular risk among patients presenting with both alpha-thalassemia trait and sickle cell trait and the indication of cardiac imagery in such patients even when considered as low-cardiovascular-risk.
\end{abstract}

\section{Case report}

We report the case of a 46-year-old female patient of Erythrean origin who was included as healthy volunteer in a French observational trial on lipid metabolism during which blood analyses and Cardiac Magnetic Resonance Imaging (cMRI) were performed. She had no known prior medical history or cardiovascular symptoms and her only cardiovascular risk factor was a light smoking habit $(<4$ pack-years) with normal lipid levels (total-cholesterol $=162 \mathrm{mg} / \mathrm{dL}$, LDL-cholesterol $=94 \mathrm{mg} / \mathrm{dL}$, HDLcholesterol $=53 \mathrm{mg} / \mathrm{dL}$, triglycerides $=74 \mathrm{mg} / \mathrm{dL}$ ), normal fasting glucose $(4.8 \mathrm{mmol} / \mathrm{L})$ and normal blood pressure (systolic 119 $\mathrm{mmHg}$, diastolic $70 \mathrm{mmHg}$ ). Her Framingham risk for cardiovascular ischemic events was very low (less than $1 \%$ over 10 years). She had previously been included as a healthy volunteer in other studies and had never been diagnosed with any medical condition. Electro Cardio Gram (ECG) at inclusion did not show any sign of existing ischemia. Tran's thoracic echocardiography was considered normal, without any left ventricle wall anomaly. cMRI revealed subendocardial late gadolinium enhancement in one lateroapical segment (Figure 1).

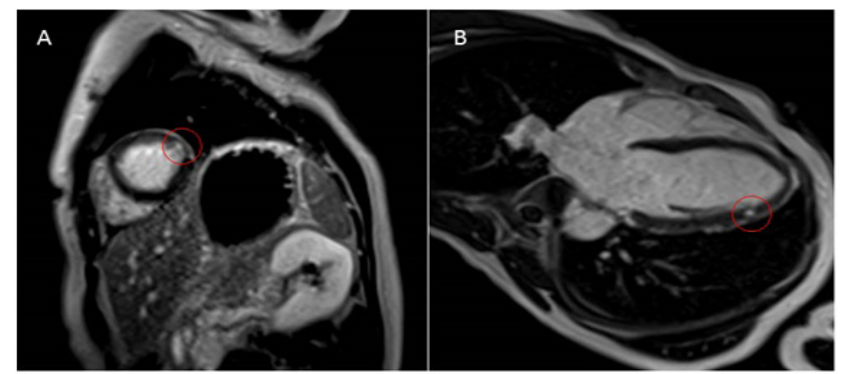

Figure 1: Cardiac magnetic resonance imaging showing focal subendocardial late gadolinium enhancement in one apical-lateral segment $(75 \%$ transmurality). A) short axis view of the left ventricle with late gadolinium enhancement imaging using a Phase Sensitive Inversion Recovery (PSIR) sequence, 10 minutes after gadolinium infusion; B) F chamber view in PSIR sequence, 10 minutes after gadolinium infusion.

Compatible with localized silent myocardial infarction. Subsequent computed tomography coronary angiography did not show any coronary lesionsor plaques and coronary calcium score was 0. Blood analysis showed normal hemoglobin $(\mathrm{Hb})$ at $13.2 \mathrm{~g} /$ $\mathrm{dL}$ and $\mathrm{Hb}$ electrophoresis revealed a previously unknown $\mathrm{HbS}$ proportion of $23.8 \%$. Further genetic analyses finally showed she 


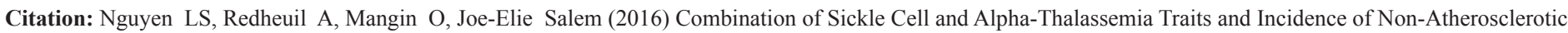
Myocardial Infarction in a Young Woman, Beyond Coincidence? Cardiolog Res Cardiovasc Med 1: 109. DOI: 10.29011/2575-7083.000009

carriedthe alpha-thalassemia trait (ATT)(homozygous deletion of locus -3.7) and sickle cell trait (heterozygous for beta-globin mutation $6 \mathrm{Glu}->\mathrm{Val})$, which had never been diagnosed before. She was later treated in secondary prevention by low-dose aspirin $(75 \mathrm{mg} /$ day) and remained asymptomatic during a 6-month follow-up.

\section{Discussion}

\section{Etiology and demographics}

Association between alpha-thalassemia and sickle cell trait is frequent with a $10 \%$ estimated prevalence,in sub-Saharan Africa from where our patient originates [1]. We hereafter discuss this association with cardiovascular outcomes.

\section{Clinical and Imaging findings}

While alpha-thalassemia major and intermedia (=hemoglobin $\mathrm{H}$ disease) have been associated with an increased thrombotic risk [2], alpha-thalassemia minor (=alpha-thalassemia trait) is not considered to increase the risk of ischemic or thrombotic events. Similarly, sickle cell disease is associated with non-atherosclerotic myocardial infarction but sickle cell trait has not been shown to be associated with an increased risk of ischemic events [3].

On the other hand, sickle cell trait carriers have an increased risk of sudden death of unclear patho physiology [4].This risk is greater during intensive physical exercise. A proposed mechanism is a lowering of $\mathrm{pH}$, an increase in body temperature and concomitant dehydration, which are thought to initiate intravascular sickling due to $\mathrm{HbS}$ polymerization. This results in an increase of concentrations of deoxygenized $\mathrm{HbS}$ leading to diffuse micro vascular obstruction [5].

The most prevalent cause of sudden death in this setting is fatal arrhythmia associated with ischemic heart disease [6]. Deriving from our case, we hereafter suggest a potential series of events, which may lead to sudden death among sickle cell trait carriers.

Cardiac MRI, a highly sensitive non-invasive myocardial imaging technique, demonstrated the presence of localized silent myocardial infarction. Mechanisms of this infarction have been suggested in the context of sickle cell trait: a/rheological factors of altered viscosity and membrane flexibility contributing to microcirculatory stasis; b/lower platelet survival during sickle cell crisis and c/vasospasm [7].

Our patient being a mild smoker, she had an increased procoagulant state [8]. This prothrombotic, proatherogenic state may in turn have favored the formation of micro-thrombi, especially in the distal portion of the myocardial vasculature. Combining this procoagulant state with sickle cell trait may explain whythe infarction remained localized without any other signs of atherosclerosis. This is a common feature of infarction among patients presenting with sickle cell disease [3].
This myocardial scar could then represent a substrate for potential ventricular arrhythmia, and physical exercise would increase the risk of sudden death.

\section{Treatment and prognosis}

Concerning specific treatment, no guideline exists on the use of aspirin for the prophylaxis of ischemic events. A study on prevention of stroke among patients suffering from sickle cell disease is ongoing but results have yet to be published (NCT00178464).

Prognosis of silent myocardial infarction is hard to assess; as by definition, it is asymptomatic. However, with an estimated prevalence of $10 \%$ carriers of both sickle-cell and alpha-thalassemia traits in sub-Saharan Africa and a sudden death rate of $0.8 / 1000$ person-year, the annual rate of sudden death associated with this disease would be tremendous.

\section{Differential diagnosis}

Silent myocardial infarction can of course be caused by regular cardiovascular risk factors such as smoking in this particular case. Thus, it would be relevant to conduct a large study on carriers of sickle-cell and alpha-thalassemia traits regarding ischemic cardiac disease and independent-related risk factors.

\section{Teaching point}

Sickle-cell trait is carried by millions of people worldwide. Stratifying their cardiovascular risk may allow to better prevent adverse outcomes in such patients and primary prevention treatment such as with low-dose aspirin needs to be tested when sickle cell trait is associated with other cardiovascular risk factors. Indeed, indirect evidence supports the hypothesis that such patients may have an increased risk of sudden death.

This case raises the importance and pertinence of performing cMRI among asymptomatic patients, and particularly those at higher cardiovascular risk. Patients presenting sickle-cell and alpha-thalassemia traits may be included in this category.
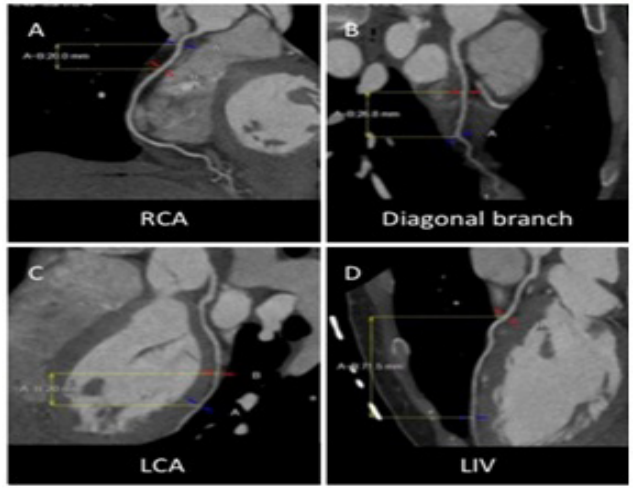

Figure 2: Computed tomography coronary angiography showing normal coronary arteries with no plaque and a global calcium coronary score $=0$. A) RCA: right coronary artery; B) diagonal branch; C) LCA: left coronaryartery; D) LIV: left interventricular coronary artery. 
Citation: Nguyen LS, Redheuil A, Mangin O, Joe-Elie Salem (2016) Combination of Sickle Cell and Alpha-Thalassemia Traits and Incidence of Non-Atherosclerotic Myocardial Infarction in a Young Woman, Beyond Coincidence? Cardiolog Res Cardiovasc Med 1: 109. DOI: 10.29011/2575-7083.000009

\section{References}

1. Lubega I, Ndugwa CM, Mworozi EA, Tumwine JK (2015) Alpha thalassemia among sickle cell anaemia patients in Kampala, Uganda. African health sciences 15: 682-689.

2. Sirachainan N (2013) Thalassemia and the hypercoagulable state. Thrombosis research 132: 637-641.

3. Martin CR, Johnson CS, Cobb C, Tatter D, Haywood LJ (1996) Myocardial infarction in sickle cell disease. J Natl Med Assoc 88: 428-432.

4. Mitchell BL (2007) Sickle cell trait and sudden death--bringing it home. Journal of the National Medical Association 99: 300-305.

5. Kark JA, Posey DM, Schumacher HR, Ruehle CJ (1987) Sickle-cell trait as a risk factor for sudden death in physical training. The New England journal of medicine 317: 781-787.
6. Myerburg RJ and Junttila MJ (2012) Sudden Cardiac Death Caused by Coronary Heart Disease. Circulation 125: 1043-1052

7. Wilkes D, Donner R, Black I, Carabello BA (1985) Variant angina in an 11 year old boy. Journal of the American College of Cardiology 5: 761-764

8. Ikonomidis I, Lekakis J, Vamvakou G, Andreotti F, Nihoyannopoulos $P$ ( 2005) Cigarette smoking is associated with increased circulating proinflammatory and procoagulant markers in patients with chronic coronary artery disease. American Heart Journal 149: 832-839. 